\title{
Clinical outcomes using ClearPoint interventional MRI for deep brain stimulation lead placement in Parkinson's disease
}

\author{
Jill L. Ostrem, MD, ${ }^{1}$ Nathan Ziman, BS, ${ }^{1}$ Nicholas B. Galifianakis, MD, ${ }^{1}$ Philip A. Starr, MD, PhD, ${ }^{2}$ \\ Marta San Luciano, MD, ${ }^{1}$ Maya Katz, MD, ${ }^{1}$ Caroline A. Racine, PhD, ${ }^{2}$ Alastair J. Martin, PhD, ${ }^{3}$ \\ Leslie C. Markun, MS, ${ }^{1}$ and Paul S. Larson, MD²
} 'Surgical Movement Disorders Center, Department of Neurology; and Departments of ${ }^{2}$ Neurological Surgery and ${ }^{3}$ Radiology,
University of California, San Francisco, California

OBJECTIVE The ClearPoint real-time interventional MRI-guided methodology for deep brain stimulation (DBS) lead placement may offer advantages to frame-based approaches and allow accurate implantation under general anesthesia. In this study, the authors assessed the safety and efficacy of DBS in Parkinson's disease (PD) using this surgical method.

METHODS This was a prospective single-center study of bilateral DBS therapy in patients with advanced PD and motor fluctuations. Symptom severity was evaluated at baseline and 12 months postimplantation using the change in Unified Parkinson's Disease Rating Scale (UPDRS) Part III "off" medication score as the primary outcome variable.

RESULTS Twenty-six PD patients (15 men and 11 women) were enrolled from 2010 to 2013 . Twenty patients were followed for 12 months (16 with a subthalamic nucleus target and 4 with an internal globus pallidus target). The mean UPDRS Part III "off" medication score improved from $40.75 \pm 10.9$ to $24.35 \pm 8.8$ ( $p=0.001)$. "On" medication time without troublesome dyskinesia increased $5.2 \pm 2.6$ hours per day $(p=0.0002)$. UPDRS Parts II and IV, total UPDRS score, and dyskinesia rating scale "on" medication scores also significantly improved $(p<0.01)$. The mean levodopa equivalent daily dose decreased from $1072.5 \pm 392 \mathrm{mg}$ to $828.25 \pm 492 \mathrm{mg}(p=0.046)$. No significant cognitive or mood declines were observed. A single brain penetration was used for placement of all leads, and the mean targeting error was $0.6 \pm 0.3 \mathrm{~mm}$. There were 3 serious adverse events (1 DBS hardware-related infection, 1 lead fracture, and 1 unrelated death).

CONCLUSIONS DBS leads placed using the ClearPoint interventional real-time MRI-guided method resulted in highly accurate lead placement and outcomes comparable to those seen with frame-based approaches.

Clinical trial registration no.: NCT00792532 (clinicaltrials.gov)

http://thejns.org/doi/abs/10.3171/2015.4.JNS15173

KEY WORDS Parkinson's disease; deep brain stimulation; interventional MRI; ClearPoint; outcomes; functional neurosurgery

$\mathrm{D}$ EEP brain stimulation (DBS) has been shown to be a highly effective treatment option for medicationrefractory Parkinson's disease (PD) patients experiencing motor fluctuations and dyskinesia. $5,15,18,21,22,26,31$ Clinical outcomes with DBS are critically dependent on the exact lead placement in the intended brain target (dorsal lateral subthalamic nucleus [STN] or posterior [motor] area of the internal globus pallidus [GPi]), but surgical methods to achieve acceptable placement are not standard- ized. The traditional method for DBS lead implantation involves the use of preoperative brain images registered in a stereotactic coordinate system, and physiological localization using microelectrode-guided mapping of the target regions while patients are awake..$^{28}$ This method poses challenges when patients are not able to tolerate and/or cooperate with awake surgery (severe "off" medication symptoms, anxiety, pain).

Recently a new method has been developed for implan-

ABBREVIATIONS AP = anteroposterior; DBS = deep brain stimulation; CGI = Clinical Global Impression; GPi = internal globus pallidus; iMRI = interventional MRI; IPG = implantable pulse generator; LEDD = levodopa equivalent daily dose; MER = microelectrode recording; PD = Parkinson's disease; PDQ-39 = Parkinson's Disease Questionnaire-39; SF-36 = 36-Item Short Form Health Survey; STN = subthalamic nucleus; UPDRS = Unified Parkinson's Disease Rating Scale.

SUBMITTED January 26, 2015. ACCEPTED April 9, 2015.

INCLUDE WHEN CITING Published online October 23, 2015; DOI: 10.3171/2015.4.JNS15173. 
tation of DBS leads using real-time interventional MRI (iMRI) guidance in conjunction with a skull-mounted aiming device without the use of microelectrode recordings or intraoperative test stimulation. ${ }^{8}$ The procedure is performed within the bore of a high-field diagnostic magnet in a radiology suite. Our initial work on iMRIguided DBS implantation used a skull-mounted aiming device (Nexframe, Medtronic, Inc.), ${ }^{24,30}$ which was not specifically designed for iMRI applications. A secondgeneration device was developed (ClearPoint, MRI Interventions, Inc.) with improved mechanical controls and an integrated software package intended to improve ease of use and accuracy of targeting. ${ }^{16}$ We recently published our experience using the ClearPoint system to implant DBS electrodes using iMRI in a series of pediatric dystonia patients with excellent outcomes. ${ }^{29}$ In this prospective study we describe the use of the ClearPoint system to place DBS leads in adults with PD and report the clinical outcomes 12 months after surgery.

\section{Methods}

\section{Patient Selection and Clinical Characterization}

Patients were recruited through the University of California, San Francisco, Surgical Movement Disorders Center. Patients requiring bilateral DBS (either STN or GPi) and expressing interest in having DBS leads placed using the iMRI method were considered for study enrollment. The determination of brain target was based on a multidisciplinary team discussion. GPi leads were chosen in 4 patients based on the presence of significant dyskinesia, stable but underlying mood complaints, and the clinical desire to avoid levodopa reduction after surgery due to nonmotor fluctuations. Inclusion criteria were a diagnosis of idiopathic PD with the presence of at least 2 of the 3 cardinal motor features (resting tremor, bradykinesia, or rigidity), disease duration longer than 5 years, age older than 21 years, robust response to levodopa with clearly defined "on" medication periods, persistent disabling symptoms (motor fluctuations, with disabling "off" periods or dyskinesia despite optimal medical therapy), a minimum Unified Parkinson's Disease Rating Scale (UPDRS) ${ }^{6}$ Part III "off" medication score of 25, stable medical therapy for at least 1 month prior to baseline, and ability to comply with follow-up visits. Exclusion criteria were intracranial abnormalities contraindicating surgery, medical contraindications to surgery or MRI, clinical evidence of an atypical parkinsonian syndrome, active alcohol or drug abuse, pregnancy, dementia or significant cognitive impairment, uncontrolled mood disorder, and inability to speak or read English.

The primary outcome measure was the change in "off" medication UPDRS motor score from baseline to 12 months after DBS. For "off" medication testing, PD medications were withheld for longer than 12 hours. Secondary outcome measures studied included changes from baseline to 12 months using the following scales/tests: UPDRS Parts I, II, and III "on" medications, Part IV subscales, and total UPDRS score; modified dyskinesia rating scale in both the "off" and "on" medication states; ${ }^{7}$ PD Hauser Diary ${ }^{11}$ (2 consecutive days, requiring the patient to determine if he or she was in 1 of 5 states for every 30 minutes: asleep, "off," "on" without dyskinesia, "on" with mild dyskinesia, and "on" with troublesome dyskinesia); Parkinson's Disease Questionnaire-39 (PDQ-39);25 36-Item Short Form Health Survey (SF-36) version 2; and Clinical Global Impression (CGI) Scale. ${ }^{4}$ Change in levodopa equivalent daily dose (LEDD), device programming settings, active contact location, and adverse events were also recorded at baseline and 12 months. Patients also underwent comprehensive neuropsychological evaluation in the "on" medication state at baseline and 12 months using the following battery: Montreal Cognitive Assessment, ${ }^{20}$ portions of the Neuropsychological Assessment Battery, portions of the DelisKaplan Executive Function Scale, Symbol-Digit Modality Test, Rey-Osterrieth Complex Figure, Boston Naming Test, Letter and Animal Fluency, Beck Depression Inventory, ${ }^{2}$ and Beck Anxiety Inventory. ${ }^{1}$

\section{Surgical Procedure: Brain Leads}

DBS leads were implanted using a novel skull-mounted aiming device in conjunction with dedicated software (ClearPoint system), used within a 1.5-T diagnostic MRI scanner (Philips Intera), under general anesthesia without physiological testing (Fig. 1). One patient underwent staged implantation (leads placed 5 weeks apart) and all others had bilateral simultaneous implants. The main features of the ClearPoint system have been previously described in technical reports. ${ }^{16,29}$ The implantable pulse

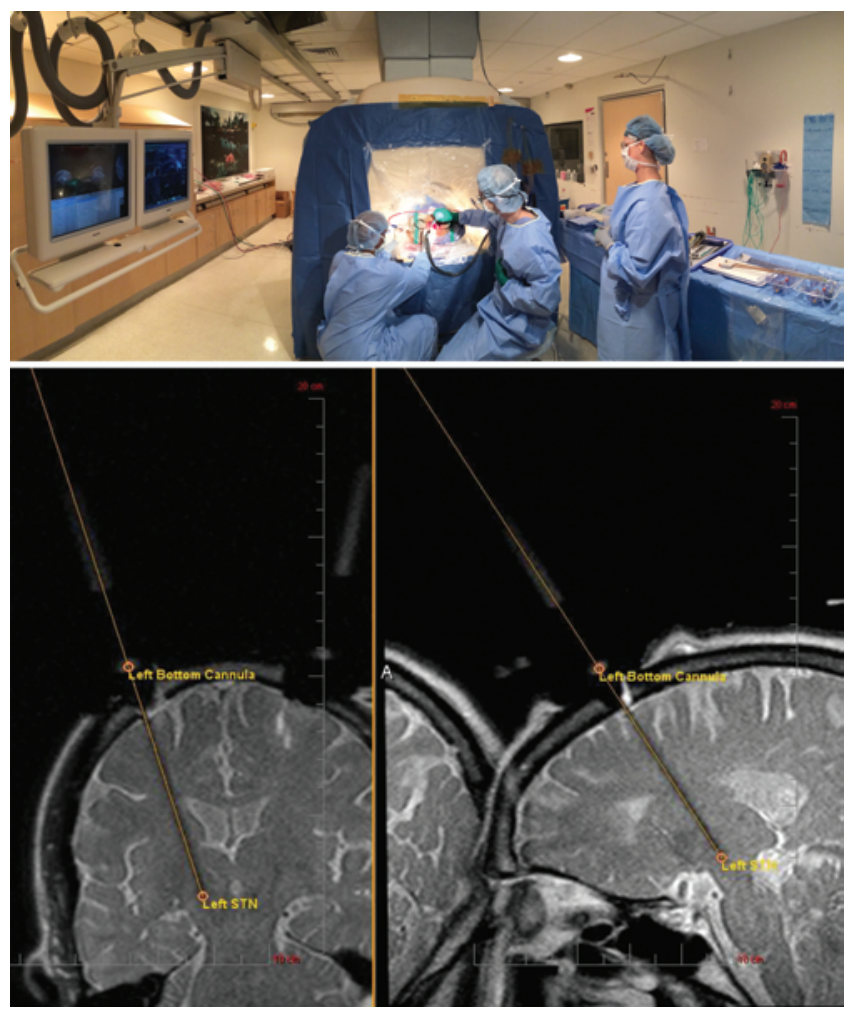

FIG. 1. Upper: Diagnostic 1.5-T MRI radiology suite during iMRI-guided implantation. Lower: Screen shot of the ClearPoint software during STN implantation. The artifact of the ceramic stylet and peel-away sheath can be seen behind the orange line indicating the planned trajectory in coronal and sagittal views. 
generators (IPGs) and lead extenders were placed in a separate inpatient or outpatient procedure 1-3 weeks after lead implantation.

\section{Evaluation of Lead Placement Accuracy}

We consider the most clinically relevant measure of lead placement accuracy to be the "radial error," defined as the $2 \mathrm{D}$ vector difference between the intended and actual lead placement measured in the axial plane used for anatomical targeting. ${ }^{29}$ 3D vector errors between intended tip and actual tip location are less clinically relevant, as small lead misplacements $(<2 \mathrm{~mm})$ along the axis of implantation can be corrected by selection of a different active contact along the quadripolar lead. The actual anterior commissure-posterior commissure coordinates of the active contact were measured using FrameLink software (Medtronic, Inc.) as described previously. ${ }^{28}$

\section{DBS Programming}

Neurostimulator programming was initiated 1-2 weeks after implantation of the pulse generator. All electrodes were sequentially activated and tested separately in unipolar mode. Voltage-limiting adverse effects were noted. The electrode(s) with the greatest therapeutic effect were chosen for chronic stimulation. For patients in whom no clinical improvement was observed during the initial programming session, the electrode(s) within the dorsal STN or posterior lateral GPi were chosen for chronic stimulation (typically Contact 1 ). All IPGs were initially programmed using 1 electrode in unipolar mode, at $60-\mu \mathrm{sec}$ pulse width and $130-145 \mathrm{~Hz}$. The voltage was increased until there was either no further benefit or adverse effects occurred, and then reduced slightly. Patients returned for follow-up programming visits every $1-2$ months.

\section{Statistical Analysis}

Data analyses were performed using STATA 12 (StataCorp LP). All scores were compared using the 2-tailed paired t-test or nonparametric equivalent with a significance level set at 0.05 . Using a repeated-measures approach, a 2-tailed test and alpha value set at 0.05 , and an estimated clinically significant effect size of $30 \%$ change in UPDRS "off" scores, we had greater than $95 \%$ power to detect a difference if we included 20 patients. Active electrode location at final follow-up was determined using the patient's postoperative MRI study and calculating the point of stimulation in anterior commissure-posterior commissure coordinates relative to the midcommissural point.

\section{Institutional Review Board Approval and Informed Consent}

The UCSF institutional review board approved the study, and all patients provided written informed consent. The trial was registered with clinicaltrials.gov (clinical trial registration no. NCT00792532).

\section{Results \\ Patient Characteristics}

Patient characteristics are summarized in Table 1.
Twenty-six patients with advanced PD (15 men and 11 women) were enrolled in this prospective study from 2010 to 2013. The mean age at time of surgery was $63.2 \pm 6.8$ years, and the duration of PD was $10.8 \pm 2.9$ years. Twenty patients had follow-up data available at 12 months (16 with an STN target and 4 with a GPi target).

Six patients did not complete the study for a variety of reasons (4 in the STN group and 2 in the GPi group). One patient developed a pulse generator infection, which spread to the connector site and required explantation of the DBS system. One patient developed a lead fracture requiring replacement and therefore was withdrawn from the study. Two patients withdrew from the study due to financial burdens of traveling to San Francisco. One patient died of unknown causes after falling out of bed. One patient underwent unilateral implantation only and did not go on to have the second lead placed and therefore became ineligible for the study (see Table 2).

Patients included in the analysis of outcomes after surgery $(n=20)$ had a robust response to dopaminergic medications at baseline (mean UPDRS Part III "off" score $40.75 \pm 10.9$, mean UPDRS Part III “on" score $20.95 \pm$ 9.8) $(\mathrm{p}=0.0001)$, reflecting a mean $47.7 \%$ improvement. The average Montreal Cognitive Assessment score was 26 (range 18-30). On detailed neuropsychological evaluation, scores were variable across individuals, but as a group they showed only mild $(\mathrm{z}>-1.0)$ difficulties in areas typically observed in PD (visual attention, processing speed, verbal recall, visual memory, complex figure copy, and executive function). The patients on average self-reported minimal depression (Beck Depression Inventory-II mean $9.55 \pm 7.1$ ) and mild anxiety (Beck Anxiety Inventory mean $11.40 \pm 5.7)$.

\section{Clinical Outcomes UPDRS}

At 12 months the total mean UPDRS III (motor) "off" medication subscore for patients improved from $40.75 \pm$ 10.9 to $24.35 \pm 8.8(p=0.001)$, reflecting a mean $40.2 \%$ improvement meeting the primary end point of the study.

UPDRS Parts II and IV and total UPDRS scores were also significantly improved at 12 months $(\mathrm{p}<0.001$, $\mathrm{p}<$ 0.001 , and $p=0.0027$, respectively) (Fig. 2). The UPDRS Part III "on" medication was not significantly improved ( $\mathrm{p}$ $=0.101$ ). Dyskinesia significantly improved after surgery, measured by the change in the severity scale of the modified dyskinesia scale score in the "on" medication state after surgery (baseline $1.05 \pm 0.97$ to $0.26 \pm 0.56$ at 12 months) $(\mathrm{p}=0.007){ }^{9}$

\section{PD Hauser Diary}

Two patients had only partially completed diaries, and their data were not included in the analysis. The "on" without dyskinesia and the "on" with mild dyskinesia states were combined to create the "on" without troublesome dyskinesia category. Diary data were normalized to a 16hour waking time per day. "Off" time decreased from 4.31 \pm 2.96 hours per day to $1.96 \pm 2.5$ hours per day $(p=0.04)$. "On" time without troublesome dyskinesia increased from $8.64 \pm 2.7$ hours per day to $13.68 \pm 2.58$ hours per day 
TABLE 1. Baseline characteristics

\begin{tabular}{|c|c|c|c|c|c|c|c|c|}
\hline Case No. & Age (yrs), Sex & $\begin{array}{c}\text { Duration of } \\
\text { PD (yrs) }\end{array}$ & $\begin{array}{l}\text { UPDRS III "Off" } \\
\text { Score }\end{array}$ & $\begin{array}{l}\text { UPDRS III } \\
\text { "On" Score }\end{array}$ & $\begin{array}{l}\% \text { Change in } \\
\text { UPDRS Score }\end{array}$ & UPDRS Total & $\begin{array}{l}\text { Hoehn \& Yahr } \\
\text { Off Stage }\end{array}$ & $\operatorname{LEDD}(\mathrm{mg})^{\star}$ \\
\hline $1 \dagger$ & $59, F$ & 10 & 27 & 8 & 70.3 & 61 & 2.0 & 1200 \\
\hline 2 & $49, \mathrm{~F}$ & 12 & 43 & 14 & 67.4 & 72 & 2.0 & 755 \\
\hline 3 & $72, \mathrm{M}$ & 7 & 30 & 16 & 46.7 & 58 & 2.0 & 875 \\
\hline $4 \dagger$ & $61, M$ & 14 & 40 & 20 & 50.0 & 81 & 2.5 & 1050 \\
\hline $5 \dagger$ & $71, \mathrm{~F}$ & 13 & 39 & 16 & 59.0 & 64 & 3.0 & 1510 \\
\hline 6 & $56, M$ & 12 & 33 & 17 & 48.5 & 59 & 2.0 & 840 \\
\hline 7 & $64, \mathrm{M}$ & 14 & 56 & 40 & 28.6 & 92 & 3.0 & 1620 \\
\hline $8 † \ddagger$ & $59, \mathrm{~F}$ & 9 & 47 & 22 & 53.2 & 90 & 3.0 & 1460 \\
\hline 9 & $64, F$ & 10 & 29 & 15 & 48.3 & 60 & 2.0 & 450 \\
\hline 10 & $59, \mathrm{M}$ & 14 & 36 & 24 & 33.3 & 57 & 2.0 & 1210 \\
\hline 11 & $70, \mathrm{~F}$ & 11 & 38 & 23 & 39.5 & 55 & 2.0 & 1535 \\
\hline 12 & $56, \mathrm{M}$ & 4 & 67 & 46 & 31.3 & 91 & 4.0 & 300 \\
\hline $13 \dagger$ & $65, \mathrm{~F}$ & 11 & 40 & 14 & 65.0 & 70 & 2.0 & 300 \\
\hline 14 & $63, \mathrm{M}$ & 8 & 45 & 21 & 53.3 & 75 & 2.0 & 1510 \\
\hline 15 & $64, \mathrm{M}$ & 8 & 30 & 15 & 50.0 & 60 & 2.0 & 900 \\
\hline $16 \ddagger$ & $68, M$ & 10 & 47 & 36 & 23.4 & 94 & 2.0 & 800 \\
\hline $17 \dagger \ddagger$ & $71, \mathrm{~F}$ & 14 & 36 & 21 & 41.7 & 69 & 3.0 & 1060 \\
\hline 18 & $63, F$ & 11 & 35 & 13 & 62.9 & 64 & 2.5 & 775 \\
\hline 19 & $71, \mathrm{M}$ & 17 & 35 & 18 & 48.6 & 55 & 2.5 & 1000 \\
\hline $20 \dagger$ & $68, M$ & 11 & 49 & 25 & 49.0 & 84 & 4.0 & 950 \\
\hline 21 & $61, M$ & 7 & 54 & 23 & 57.4 & 88 & 2.0 & 1200 \\
\hline $22 \dagger$ & $63, F$ & 6 & 43 & 10 & 76.7 & 58 & 4.0 & 1250 \\
\hline $23 \dagger$ & $68, F$ & 13 & 29 & 12 & 58.6 & 56 & 4.0 & 1060 \\
\hline 24 & $44, \mathrm{M}$ & 14 & 54 & 25 & 53.7 & 95 & 3.0 & 1900 \\
\hline 25 & $66, M$ & 11 & 32 & 11 & 65.6 & 62 & 2.0 & 1220 \\
\hline 26 & $67, \mathrm{M}$ & 11 & 30 & 15 & 50.0 & 59 & 3.0 & 1300 \\
\hline Mean (SD) & $63.2(6.8)$ & $10.8(2.9)$ & $40.1(10.0)$ & $20.0(9.1)$ & $51.2(13.0)$ & $70.3(14.1)$ & $2.6(0.7)$ & $1078.1(393.7)$ \\
\hline
\end{tabular}

* LEDD = a dose of $100 \mathrm{mg}$ levodopa, which is is equal to $125 \mathrm{mg}$ controlled-release levodopa, $10 \mathrm{mg}$ bromocriptine, $1 \mathrm{mg}$ pergolide, $4 \mathrm{mg}$ ropinirole, $100 \mathrm{mg}$ amantadine, $333 \mathrm{mg}$ entacapone, $1 \mathrm{mg}$ pramipexole, and $80 \mathrm{mg}$ Stalevo, according to Wenzelburger et al., 2002.

$\dagger$ Patients without 12-month follow-up.

$\ddagger$ GPi target.

$(\mathrm{p}=0.0002)$. "On" time with severe dyskinesia decreased from $1.89 \pm 1.86$ to $0.18 \pm 0.57$ hours per day $(\mathrm{p}=0.0008)$ (Fig. 2).

\section{Clinical Global Impression Scores}

The CGI Severity Scale showed significant mean improvement from baseline to the 12-month assessment (3.71 \pm 0.71 to $3.1 \pm 0.71, \mathrm{p}=0.012$, investigator rated; $3.89 \pm$ 1.1 to $2.8 \pm 1.1, \mathrm{p}=0.007$, patient rated). The CGI Change Scale showed investigators believed $95 \%$ of patients were "very much improved" or "much improved" 12 months after surgery; $80 \%$ of patients also believed they were "very much improved" or "much improved" 12 months after surgery.

\section{Quality of Life Scores}

The PDQ-39 only showed significant improvement in the communication subscore $(\mathrm{p}<0.036)$ and a trend for improvement in the activities of daily living subscore $(\mathrm{p}=0.06)$ at 12 months. The SF-36 version 2 showed a trend for improvement in physical function subscore at 12 months $(\mathrm{p}=0.07)$.

\section{LEDD}

The mean LEDD at baseline was $1072.5 \pm 392 \mathrm{mg}$ and decreased to $828.25 \pm 492 \mathrm{mg}$ after surgery $(21.13 \%$ reduction) $(\mathrm{p}=0.046)$. There were no major differences in the change in LEDD for the patients treated with STN versus $\mathrm{GPi}$.

\section{Neuropsychological Testing}

Most patients did not demonstrate significant declines across various cognitive domains after DBS, and in fact some showed improvements after 1 year. There were mild declines (>1 SD) in verbal category fluency in 35\% of patients, which is a frequent finding after DBS. There were 
TABLE 2. Mean active contact location

\begin{tabular}{|c|c|c|c|c|c|c|}
\hline \multirow[b]{2}{*}{ Hemisphere } & \multicolumn{3}{|c|}{ STN $(n=32)$} & \multicolumn{3}{|c|}{ GPi $(n=8)$} \\
\hline & X (lateral) & $\mathrm{Y}(\mathrm{AP})$ & Z (vertical) & X (lateral) & $\mathrm{Y}(\mathrm{AP})$ & Z (vertical) \\
\hline Left & $-12.1 \pm 1.1$ & $-1.5 \pm 1.5$ & $-2.1 \pm 1.3$ & $-21.6 \pm 1.9$ & $4.3 \pm 1.4$ & $-0.9 \pm 0.9$ \\
\hline Right & $11.9 \pm 1.4$ & $-1.7 \pm 2.1$ & $-2.5 \pm 1.6$ & $22.6 \pm 1.6$ & $4.4 \pm 1.8$ & $-0.5 \pm 0.6$ \\
\hline
\end{tabular}

also mild declines (<1 SD) in complex figure copy (35\%) and on 1 delayed memory task (30\%). Anxiety and depression were stable or improved in $85 \%$ of patients.

\section{Stimulation Parameters}

The average stimulation parameters were $2.73 \mathrm{~V}, 61.8$ $\mu$ sec, and $138.4 \mathrm{~Hz}$ for patients with STN targets and 3.93 V, $67.5 \mu \mathrm{sec}$, and $145.6 \mathrm{~Hz}$ for patients with GPi. Eighteen leads were programmed using a single monopolar mode, 10 using a double monopolar mode, 4 using a bipolar mode, and 8 using a monopolar interleaving mode.

\section{Surgical Accuracy}

A single brain penetration was used for placement of all leads. The mean $( \pm \mathrm{SD})$ radial error was $0.6 \pm 0.3 \mathrm{~mm}$. The mean active contact location is shown in Table 2.

\section{Adverse Events}

All adverse events occurring in the trial are listed in Table 3.

Serious Adverse Events. There were 3 serious adverse events. There was 1 DBS hardware-related infection originating at the pulse generator, 1 DBS lead fracture requiring replacement of the brain lead, and 1 death unrelated to the surgery or device. There were no hemorrhages. No electrodes required repositioning due to lack of clinical efficacy or stimulation-induced side effects at low voltages.
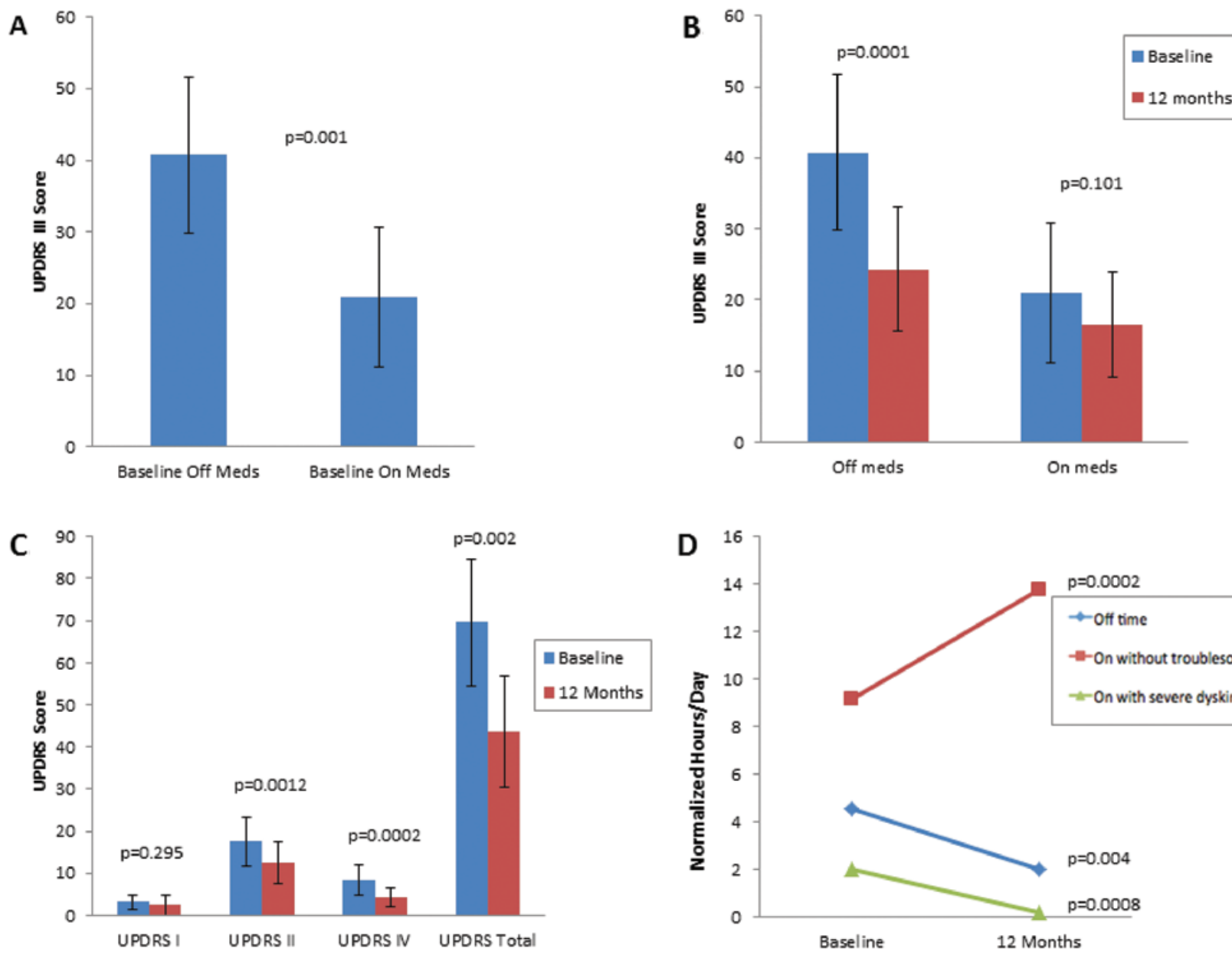

FIG. 2. Results of ClearPoint iMRI. A: Degree of dopaminergic responsiveness at baseline visit (paired t-test). B: Change in UPDRS Part III score from baseline to 12 after months after DBS (paired t-test). C: Change in UPDRS Part I, II, IV, and total scores from baseline to 12 months after DBS (paired t-test). D: Change in motoric state as measured by the mean of a 2-day PD Hauser diary from baseline to 12 months in hours per day (normalized to a 16-hour waking day). 
TABLE 3. Summary of serious and nonserious adverse events

\begin{tabular}{lccll}
\hline \multicolumn{1}{c}{ Adverse Event } & $\begin{array}{c}\text { No. of } \\
\text { Events }\end{array}$ & $\begin{array}{c}\text { No. of Patients } \\
(\%)\end{array}$ & \multicolumn{1}{c}{ Cause (no.) } & Event Outcome at 1 Yr (no. of patients) \\
\hline Serious & 3 & $3(11.5)$ & & \\
\hline Infection & 1 & $1(3.8)$ & Surgery & Hardware explanted (1) \\
\hline DBS lead fracture & 1 & $1(3.8)$ & Hardware & Lead replaced \\
\hline Unrelated death & 1 & $1(3.8)$ & Unrelated & \\
\hline Nonserious & 35 & $17(65.4)$ & & Ongoing (3), resolved (3), unchanged (2) \\
\hline Worsened balance & 8 & $8(30.7)$ & Unrelated (8) & Ongoing (3) \\
\hline Worsened dyskinesia & 4 & $3(11.5)$ & Stimulation (2), unrelated (2) & Ongoing (2), resolved(2) \\
\hline Worsening speech & 4 & $4(15.4)$ & Possibly stimulation & Resolved (3) \\
\hline Depression & 3 & $3(11.5)$ & Unrelated (3) & Ongoing (1), resolved (2) \\
\hline Anxiety & 3 & $3(11.5)$ & Unrelated (3) & Resolved (2), ongoing (1) \\
\hline Sleep disturbances & 3 & $3(11.5)$ & Unrelated (3) & Ongoing (1), resolved (1), unchanged (1) \\
\hline Dystonia & 3 & $3(11.5)$ & Unrelated (3) & Ongoing (2) \\
\hline Fatigue & 2 & $2(7.7)$ & Unrelated (2) & Ongoing \\
\hline Worsened handwriting & 1 & $1(3.8)$ & Possibly stimulation & Resolved \\
\hline Teeth grinding & 1 & $1(3.8)$ & Unrelated & Unchanged \\
\hline Weight loss & 1 & $1(3.8)$ & Possibly stimulation & Resolved \\
\hline Constipation & 1 & $1(3.8)$ & Unrelated & Antibiotics resolved (1) \\
\hline Infection & 1 & $1(3.8)$ & Surgery &
\end{tabular}

Other Adverse Events. There were 35 nonserious adverse events occurring in 17 patients. Most were felt to be unrelated to the surgery or DBS stimulation. We did observe transient worsening in dyskinesia, speech, handwriting, and weight, which were considered possibly related to stimulation throughout the trial.

\section{Discussion}

We previously reported outcomes for PD patients with DBS leads placed using iMRI and the Nexframe skullmounted aiming device. ${ }^{24,30}$ In this report we present the largest cohort to date of PD patients treated with STN or GPi DBS using the iMRI technique in conjunction with the ClearPoint system, specifically designed for use with iMRI. In this study we provide greater detailed motor and nonmotor outcome measures and a longer follow-up window (12 months).

\section{Summary of Results}

Patients experienced a mean improvement of $40.2 \%$ in the UPDRS Part III "off" medication score 1 year after surgery $(\mathrm{p}=0.001)$, thus meeting the primary end point of the study. This degree of improvement is comparable to the efficacy of STN DBS and GPi DBS for PD when leads are placed using traditional, frame-based, microelectrode recording (MER)-guided stereotactic methods (Table 4). $5,15,18,21-23,26,31$

We also found significant improvements in several secondary outcome measures. Based on PD Hauser diaries, patients had an average of 5 additional hours of "on" time without troublesome dyskinesia, and 2.3 fewer hours of "off" time. The UPDRS Part II and IV subscales and the modified dyskinesia rating in the "on" medication state all showed statistically significant improvements at 1 year, as did several quality of life measures.

TABLE 4. Change in UPDRS Part III "off" medication score across major PD DBS trials

\begin{tabular}{|c|c|c|c|c|c|c|c|c|}
\hline Authors \& Year & Study & $\begin{array}{c}\text { No. of } \\
\text { Subjects }\end{array}$ & $\begin{array}{c}\text { Mean Age } \\
(y r s)\end{array}$ & $\begin{array}{c}\text { Mean Disease } \\
\text { Duration (yrs) }\end{array}$ & $\begin{array}{l}\text { UPDRS III } \\
\text { Off Baseline }\end{array}$ & $\begin{array}{l}\text { UPDRS III } \\
\text { Off FU }\end{array}$ & $\begin{array}{c}\text { UPDRS III \% } \\
\text { Change }\end{array}$ & $\begin{array}{c}\mathrm{FU} \\
\text { (mos) }\end{array}$ \\
\hline Okun et al., 2012 & $\begin{array}{l}\text { St. Jude Constant- } \\
\text { Current study }\end{array}$ & 136 & 60 & 12 & $41-45$ & $26-30$ & $\sim 38 \%$ & 12 \\
\hline Williams et al., 2010 & PD SURG trial & 183 & 59 & 11.5 & 47.6 & 30.6 & $35.7 \%$ & 12 \\
\hline Odekerken et al., 2013 & NSTAPS study & 128 & $\begin{array}{l}59.1 \text { (GPi); } \\
\quad 60.1 \text { (STN) }\end{array}$ & $\begin{array}{l}10.8 \text { (GPi); } \\
12.0 \text { (STN) }\end{array}$ & $\begin{array}{l}43.8 \text { (GPi); } \\
\quad 44.4 \text { (STN) }\end{array}$ & $\begin{array}{l}32.4 \text { (GPi); } \\
24.1 \text { (STN) }\end{array}$ & $\begin{array}{l}26.0 \% \text { (GPi); } \\
\quad 45.7 \% \text { (STN) }\end{array}$ & 12 \\
\hline Follett et al., 2010 & VA Coop study & 299 & $\begin{array}{l}61.8 \text { (GPi); } \\
61.9 \text { (STN) }\end{array}$ & & $\begin{array}{l}41.8 \text { (GPi); } \\
\quad 43.0 \text { (STN) }\end{array}$ & $\begin{array}{l}30.0 \text { (GPi); } \\
32.1 \text { (STN) }\end{array}$ & $\begin{array}{l}28.2 \% \text { (GPi); } \\
\quad 25.4 \% \text { (STN) }\end{array}$ & 24 \\
\hline Schuepbach et al., 2013 & EARLYSTIM study & 124 & 52.9 & 7.3 & 33.2 & & $52.7 \%$ & 24 \\
\hline Present study & & 25 (20 FU) & 63.0 & 10.8 & 40.8 & 24.4 & $40.2 \%$ & 12 \\
\hline
\end{tabular}

$\mathrm{FU}=$ follow-up. 
Adverse events seen in this study were similar to what has been described using traditional, MER-guided DBS studies and with no intracranial hemorrhages. ${ }^{5,10,21,22,31,34}$

\section{Unique Aspects of iMRI}

Implantation of brain leads using the ClearPoint system and iMRI technique may have several advantages over the traditional MER-guided surgery, including increased anatomical accuracy and consistency of lead placement and fewer brain penetrations. ClearPoint uses real-time MRI to perform target selection and monitor lead placement; it does not rely on MR images obtained preoperatively, which cannot account for intraoperative brain shift due to pneumocephalus, or CT images obtained intraoperatively, which must be fused with preoperative image sets and are therefore subject to potential fusion errors. ${ }^{13,14}$ It therefore has the advantage of detecting lead placement errors as well as other intraoperative complications such as hemorrhages in real time, with shorter operative times than awake surgery. Finally, because iMRI DBS can be safely done under general anesthesia and does not require withholding of parkinsonian medications, it may broaden the accessibility to those who might not otherwise be able to tolerate awake surgery.

In this study, the technical accuracy of lead placement, as measured by the mean radial error, was $0.6 \pm 0.3 \mathrm{~mm}$. Directly comparing lead accuracy results to those of other DBS trials can be difficult as most studies have not reported accuracy of lead placement or have used different measures of accuracy. Holloway and colleagues compared the accuracy of frameless and frame-based techniques in awake, physiologically guided surgery and found mean errors in the anteroposterior (AP) and lateral directions between 1.3 and $1.6 \mathrm{~mm}$, with a mean vector error of $3.2 \pm$ $1.4 \mathrm{~mm}$ regardless of the implantation technique used..$^{5,12}$ Nakajima and colleagues, using frame-based, MRI-confirmed asleep DBS placement, reported accuracy by mean perpendicular targeting error as $1.2 \mathrm{~mm} .{ }^{19}$ Burchiel and colleagues $^{3}$ recently published a large series with electrodes placed under general anesthesia using intraoperative CT and reported the "trajectory error" as $1.27 \pm 0.87$ $\mathrm{mm}$ with 1 electrode repositioned intraoperatively for a vector error of greater than $3 \mathrm{~mm}$. The accuracy of lead placement in the current study using the iMRI technique with ClearPoint is superior to that in other published studies.

In this study, all brain leads were placed using a single pass with one brain penetration. A large, prospective study randomizing patients to either iMRI- or MER-guided technique would be necessary to definitely prove the clinical benefits of fewer brain penetrations. However, limiting the number of brain penetrations may reduce the risk of brain hemorrhage, shorten recovery time after surgery, and improve cognitive-behavioral outcomes. ${ }^{5,10,17,34}$ Few MERguided DBS outcome studies report the number of brain penetrations performed to determine a final DBS lead location. However, it is not uncommon to perform multiple MER passes to map the motor territory before placement of the final brain lead, and in most MER-guided procedures there are a minimum of 2 penetrations for each lead (one pass for MER and another pass for lead placement). ${ }^{28}$

\section{Limitations}

This study was an open-label clinical trial that did not randomize patients to surgical method or stimulation status and is therefore subject to placebo effect and selection bias. However, in hopes of minimizing selection bias and maximizing a comparison with historical controls, we designed the study using strict inclusion/exclusion criteria similar to those used in the large randomized PD DBS studies. Many patients seen at our center during the course of the study were still implanted using the ClearPoint iMRI system but were implanted "off protocol" because they did not meet the study's strict inclusion/exclusion criteria.

\section{Clinical Application}

The ClearPoint iMRI method has several advantages over traditional frame-based MER-guided DBS lead placement, especially in certain clinical settings where it is beneficial for PD patients to be asleep (severe tremor, painful "off" dystonia or rigidity, "off" anxiety). Many PD patients in the study expressed their desire to have DBS using iMRI because it did not require them to be awake for the procedure or to withhold their PD medications prior to surgery, which is typically necessary for MER-guided procedures. We have recently reported our experience using the ClearPoint system in a series of primary pediatric dystonia patients (who would also have had difficulty handling awake surgery) who also experienced excellent outcomes..$^{29}$ Disadvantages of the iMRI method include the need for specialized MR-compatible instrumentation and anesthesia equipment, as well as access to a scanner in the radiology department or an operating room. At our center, awake DBS cases include IPG placement on the same day, whereas MRI cases require a staged approach with the IPG placed several weeks later as an outpatient procedure. Some patients perceive this as a disadvantage of iMRI, as they would prefer to have the leads and IPG placed in a single setting.

\section{Conclusions}

Here for the first time we report the clinical outcomes of DBS in PD using an interventional MRI technique with an optimized skull-mounted aiming system (ClearPoint). We have shown comparable outcomes to those with frame-based microelectrode-guided surgery and a similar safety profile. We propose that this technique offers many other advantages, including possible shorter operative time required for lead placement, fewer brain penetrations than most traditional methods of DBS surgery, and greater patient comfort during the procedure.

\section{Acknowledgments}

We thank Robin Taylor, NP, and Sarah Wang, PhD, for assistance with study coordination. This study was supported in part by a grant from the Bachmann-Strauss Dystonia and Parkinson's Disease Research Foundation, from MRI Interventions, Inc., and from the NIH (R21 EB008888).

\section{References}

1. Beck AT, Epstein N, Brown G, Steer RA: An inventory for 
measuring clinical anxiety: psychometric properties. J Consult Clin Psychol 56:893-897, 1988

2. Beck AT, Ward CH, Mendelson M, Mock J, Erbaugh J: An inventory for measuring depression. Arch Gen Psychiatry 4:561-571, 1961

3. Burchiel KJ, McCartney S, Lee A, Raslan AM: Accuracy of deep brain stimulation electrode placement using intraoperative computed tomography without microelectrode recording. J Neurosurg 119:301-306, 2013

4. Busner J, Targum SD: The Clinical Global Impressions Scale: Applying a research tool in clinical practice. Psychiatry (Edgmont) 4:28-37, 2007

5. Deep-Brain Stimulation for Parkinson's Disease Study Group: Deep-brain stimulation of the subthalamic nucleus or the pars interna of the globus pallidus in Parkinson's disease. N Engl J Med 345:956-963, 2001

6. Fahn S, Elton RL: Unified Parkinson's disease rating scale, in Fahn S, Marsden CD, Goldstein M, et al (eds): Recent Developments in Parkinson's Disease. Florham Park, NJ: Macmillan Healthcare Information, 1987, Vol. 2, pp 153-163

7. Follett KA, Weaver FM, Stern M, Hur K, Harris CL, Luo P, et al: Pallidal versus subthalamic deep-brain stimulation for Parkinson's disease. N Engl J Med 362:2077-2091, 2010

8. Foltynie T, Zrinzo L, Martinez-Torres I, Tripoliti E, Petersen E, Holl E, et al: MRI-guided STN DBS in Parkinson's disease without microelectrode recording: efficacy and safety. J Neurol Neurosurg Psychiatry 82:358-363, 2011

9. Goetz CG, Stebbins GT, Shale HM, Lang AE, Chernik DA, Chmura TA, et al: Utility of an objective dyskinesia rating scale for Parkinson's disease: inter- and intrarater reliability assessment. Mov Disord 9:390-394, 1994

10. Hariz MI: Complications of deep brain stimulation surgery. Mov Disord 17 (Suppl 3):S162-S166, 2002

11. Hauser RA, Friedlander J, Zesiwicz, TA, et al: A home diary to assess functional status in patients with Parkinson's disease with motor fluctuations and dyskinesia. Clin Neuropharmacol 23:75-81, 2000

12. Holloway KL, Gaede SE, Starr PA, Rosenow JM, Ramakrishnan V, Henderson JM: Frameless stereotaxy using bone fiducial markers for deep brain stimulation. J Neurosurg 103:404-413, 2005

13. Ivan ME, Yarlagadda J, Saxena AP, Martin AJ, Starr PA, Sootsman WK, et al: Brain shift during bur hole-based procedures using interventional MRI. J Neurosurg 121:149160,2014

14. Khan MF, Mewes K, Gross RE, Skrinjar O: Assessment of brain shift related to deep brain stimulation surgery. Stereotact Funct Neurosurg 86:44-53, 2008

15. Kleiner-Fisman G, Herzog J, Fisman DN, Tamma F, Lyons KE, Pahwa R, et al: Subthalamic nucleus deep brain stimulation: summary and meta-analysis of outcomes. Mov Disord 21 (Suppl 14):S290-S304, 2006

16. Larson PS, Starr PA, Bates G, Tansey L, Richardson RM, Martin AJ: An optimized system for interventional magnetic resonance imaging-guided stereotactic surgery: preliminary evaluation of targeting accuracy. Neurosurgery 70 (1 Suppl Operative):95-103, 2012

17. Mikos A, Pavon J, Bowers D, Foote KD, Resnick AS, Fernandez $\mathrm{HH}$, et al: Factors related to extended hospital stays following deep brain stimulation for Parkinson's disease. Parkinsonism Relat Disord 16:324-328, 2010

18. Moro E, Lozano AM, Pollak P, Agid Y, Rehncrona S, Volkmann J, et al: Long-term results of a multicenter study on subthalamic and pallidal stimulation in Parkinson's disease. Mov Disord 25:578-586, 2010

19. Nakajima T, Zrinzo L, Foltynie T, Olmos IA, Taylor C, Hariz MI, et al: MRI-guided subthalamic nucleus deep brain stimulation without microelectrode recording: can we dispense with surgery under local anaesthesia? Stereotact Funct Neurosurg 89:318-325, 2011
20. Nasreddine ZS, Phillips NA, Bédirian V, et al: The Montreal Cognitive Assessment, MoCA: A brief screening tool for mild cognitive impairment. J Am Geriatr Soc 53:695-699, 2005

21. Odekerken VJ, van Laar T, Staal MJ, Mosch A, Hoffmann CF, Nijssen PC, et al: Subthalamic nucleus versus globus pallidus bilateral deep brain stimulation for advanced Parkinson's disease (NSTAPS study): a randomised controlled trial. Lancet Neurol 12:37-44, 2013

22. Okun MS, Fernandez HH, Wu SS, Kirsch-Darrow L, Bowers D, Bova F, et al: Cognition and mood in Parkinson's disease in subthalamic nucleus versus globus pallidus interna deep brain stimulation: the COMPARE trial. Ann Neurol 65:586595, 2009

23. Okun MS, Gallo BV, Mandybur G, Jagid J, Foote KD, Revilla FJ, et al: Subthalamic deep brain stimulation with a constantcurrent device in Parkinson's disease: an open-label randomised controlled trial. Lancet Neurol 11:140-149, 2012

24. Ostrem JL, Galifianakis NB, Markun LC, Grace JK, Martin AJ, Starr PA, et al: Clinical outcomes of PD patients having bilateral STN DBS using high-field interventional MR-imaging for lead placement. Clin Neurol Neurosurg 115:708-712, 2013

25. Peto V, Jenkinson C, Fitzpatrick R, Greenhall R: The development and validation of a short measure of functioning and well being for individuals with Parkinson's disease. Qual Life Res 4:241-248, 1995

26. Rodriguez-Oroz MC, Obeso JA, Lang AE, Houeto JL, Pollak $\mathrm{P}$, Rehncrona $\mathrm{S}$, et al: Bilateral deep brain stimulation in Parkinson's disease: a multicentre study with 4 years follow-up. Brain 128:2240-2249, 2005

27. Schuepbach WM, Rau J, Knudsen K, Volkmann J, Krack P, Timmermann L, et al: Neurostimulation for Parkinson's disease with early motor complications. N Engl J Med 368:610-622, 2013

28. Starr PA, Christine CW, Theodosopoulos PV, Lindsey N, Byrd D, Mosley A, et al: Implantation of deep brain stimulators into the subthalamic nucleus: technical approach and magnetic resonance imaging-verified lead locations. J Neurosurg 97:370-387, 2002

29. Starr PA, Markun LC, Larson PS, Volz MM, Martin AJ, Ostrem JL: Interventional MRI-guided deep brain stimulation in pediatric dystonia: first experience with the ClearPoint system. J Neurosurg Pediatr 14:400-408, 2014

30. Starr PA, Martin AJ, Ostrem JL, Talke P, Levesque N, Larson PS: Subthalamic nucleus deep brain stimulator placement using high-field interventional magnetic resonance imaging and a skull-mounted aiming device: technique and application accuracy. J Neurosurg 112:479-490, 2010

31. Weaver FM, Follett K, Stern M, Hur K, Harris C, Marks WJ $\mathrm{Jr}$, et al: Bilateral deep brain stimulation vs best medical therapy for patients with advanced Parkinson disease: a randomized controlled trial. JAMA 301:63-73, 2009

32. Wenzelburger R, Zhang BR, Pohle S, Klebe S, Lorenz D, Herzog J, et al: Force overflow and levodopa-induced dyskinesias in Parkinson's disease. Brain 125:871-879, 2002

33. Williams A, Gill S, Varma T, Jenkinson C, Quinn N, Mitchell R, et al: Deep brain stimulation plus best medical therapy versus best medical therapy alone for advanced Parkinson's disease (PD SURG trial): a randomised, open-label trial. Lancet Neurol 9:581-591, 2010

34. Zrinzo L, Foltynie T, Limousin P, Hariz MI: Reducing hemorrhagic complications in functional neurosurgery: a large case series and systematic literature review. J Neurosurg 116:84-94, 2012

\section{Disclosure}

The authors state the following. Dr. Ostrem receives research 
grants from NIH and MRI Interventions, a fellowship grant from Medtronic, is a consultant for Boston Scientific, Inc., and Abbvie, Inc., and receives honoraria from Allergan, Inc. Mr. Ziman receives research grant support from MRI Interventions. Dr. Starr receives research grants from NIH and MRI Interventions and a fellowship grant from Medtronic, Inc., and is a consultant for Boston Scientific, Inc. Dr. Martin has received research grant support from MRI Interventions. Ms. Markun has received project-based consulting fees from Medtronic. Dr. Larson receives research grants from NIH, MRI Interventions, and the Michael J. Fox Foundation; and honoraria from Medtronic, Inc.

\section{Author Contributions}

Conception and design: Ostrem, Starr, Larson. Acquisition of data: all authors. Analysis and interpretation of data: all authors. Drafting the article: Ostrem, Galifianakis, Starr, Larson. Critically revising the article: all authors. Reviewed submitted version of manuscript: all authors. Approved the final version of the manuscript on behalf of all authors: Ostrem. Statistical analysis: Ostrem, Ziman, Galifianakis, San Luciano. Administrative/technical/material support: Ostrem, Ziman, Markun. Study supervision: Ostrem, Starr, Larson.

\section{Correspondence}

Jill L. Ostrem, Department of Neurology, Surgical Movement Disorder Center, 1635 Divisadero St., 5th Fl., Stes. 520-530, San Francisco, CA 94115. email: jill.ostrem@ucsf.edu. 